\title{
Phylogenetic Evidence for the Taxonomic Heterogeneity of Photorhabdus luminescens
}

\author{
EMÍlIA SZÁLLÁS, ${ }^{1}$ CATHRIN KOCH,${ }^{2}$ ANDRÁS FODOR, ${ }^{1 *}$ JUTTA BURGHARDT, ${ }^{2}$ ORSOLA BUSS, ${ }^{2}$ \\ ATTILA SZENTIRMAI ${ }^{3}$ KENNETH H. NEALSON ${ }^{4}$ AND ERKO STACKEBRANDT ${ }^{2}$ \\ Department of Genetics, Eötvös University, H-1088 Budapest, ${ }^{1}$ and Department of Microbiology and Biotechnology, \\ Kossuth University, H-4010 Debrecen ${ }^{3}$ Hungary; DSMZ-Deutsche Sammlung von Mikroorganismen und \\ Zellkulturen GmbH, D-38124 Braunschweig, Germany²; and Center for Great Lake Studies, \\ University of Wisconsin-Milwaukee, Milwaukee, Wisconsin $53204^{4}$
}

\begin{abstract}
The sequences of the 16S rRNA gene of 40 strains of bacterial symbionts isolated from the nematodes Heterorhabditis spp. and seven bacterial symbionts of the nematodes Steinernema spp. which were isolated from different geographical areas, as well as the type strain of Xenorhabdus japonicus, were determined and compared to each other and to the sequences of several reference strains of members of the Enterobacteriaceae. The data confirmed the separate status of the two genera of symbionts of entomopathogenic rhabditid nematodes. The symbionts of Heterorhabditis spp. clustered with the type strain of Photorhabdus luminescens, while the symbionts of Steinernema spp. grouped with Xenorhabdus species. X. japonicus clustered with the other Xenorhabdus species. Phylogenetic analysis of 15 almost complete 16S ribosomal DNA (rDNA) sequences of the Heterorhabditis symbionts indicated that there were several subclusters. The properties correlated with these subclusters are not yet apparent, although there may be some geographical and ecological correlations. For example, among the nematode-symbiotic bacteria, the members of subclusters I and III are from southeastern and midwestern North America, respectively, while the members of subclusters II and IV are primarily from Europe and Australia, respectively. The nonsymbiotic strains of $P$. luminescens form a highly homologous subcluster by themselves. The results of DNA-DNA hybridization studies performed with a few selected strains of five of the $16 \mathrm{~S}$ rDNA subclusters support the existence of several genospecies within $P$. luminescens.
\end{abstract}

Entomopathogenic bacteria that are symbiotic with nematodes in the genera Heterorhabditis and Steinernema have been known for many years $(1,3,15,26)$, and originally these insectpathogenic bacteria were placed in the genus Xenorhabdus, with the luminous forms affiliated with the species Xenorhabdus luminescens and the nonluminous forms affiliated with several different species (Xenorhabdus nematophilus, Xenorhabdus beddingii, Xenorhabdus bovienii, Xenorhabdus japonicus, and Xenorhabdus poinarii). It was later proposed on the basis of physiological and genomic (DNA-DNA hybridization) analysis data that $X$. luminescens should be given genus status, and this taxon was designated Photorhabdus luminescens (6). All symbiotic $P$. luminescens strains to date have been isolated from nematodes belonging to the heterorhabditis group, while the Xenorhabdus species have been obtained from nematodes belonging to the genus Steinernema. Recently, several nonsymbiotic isolates of $X$. luminescens were described (13). These strains were obtained from human wounds, and while they share many properties with other $X$. luminescens strains, they are apparently not associated with nematodes. Although the genus Photorhabdus has been proposed (6), many of the details concerning the phylogeny and taxonomy of the genera Xenorhabdus and Photorhabdus have not yet been settled (23). The issues of phylogeny, taxonomy, and identification of strains take on importance for the following reasons: (i) these bacteria are economically important because of their ability to kill a variety of insect prey (9-11); (ii) these bacteria are often (but not always) symbiotically associated with nematode hosts, and the nature of the host-bacterium symbiosis has not yet been

* Corresponding author. Mailing address: Department of Genetics, Eötvös University, Múzeum krt. 4/A, H-1088 Budapest, Hungary. Phone: 361266 1296. Fax: 361266 2694. E-mail: fodoran@ludens.elte .hu. precisely defined; (iii) these bacteria form phase variants $(2,4$, 5) that are difficult to identify but economically important because of the formation of symbiotic relationships with the infective forms of their nematode hosts and the ability of the bacteria to support efficient nematode growth; and (iv) these bacteria have also been isolated (as free-living forms) from human wounds (13), suggesting that their ecology, as a group, may be more complex than previously imagined. With regard to the last point, no analyses of the $16 \mathrm{~S}$ ribosomal DNA (rDNA) genes of the human wound isolates have been described yet.

In previous work on these groups of bacteria, Rainey et al. (23) were unable to unambiguously separate the genera Xenorhabdus and Photorhabdus on the basis of $16 \mathrm{~S}$ rDNA sequence analyses and suggested that the addition of more strains, especially strains of $P$. luminescens, might allow workers to settle the issue of genus status. Accordingly, here we present data from $16 \mathrm{~S}$ rDNA analyses of several other $P$. luminescens strains, including isolates from Europe, North America, Australia, and Israel, as well as both symbiotic and nonsymbiotic isolates. The addition of these strains resulted in a data set that allows us to support with more certainty the separation of these organisms into two genera, and furthermore, the data suggest that there may be some subclusters worthy of genospecies rank within the species $P$. luminescens.

\section{MATERIALS AND METHODS}

Bacterial strains. 16S rDNAs were isolated from 40 Photorhabdus strains, $X$. japonicus IAM $14265^{\mathrm{T}}(\mathrm{T}=$ type strain) $(21)$, three strains of $X$. nematophilus, and four strains of $X$. bovienii. The designations, origins, and hosts of the strains, the lengths of the 16S rDNA stretches analyzed and the 16S rDNA accession numbers are listed in Table 1. The sequences of $P$. luminescens DSM $3368^{\text {Th }}$ (accession number X82248), DSM 3369 (X82249), and HSH2 (X82250), $X$ nematophilus DSM $3370^{\mathrm{T}}$ (X82251), X. bovienii DSM $4766^{\mathrm{T}}$ (X82252), X. poinari DSM $4768^{\mathrm{T}}$ (X82253),X beddingii DSM $4764^{\mathrm{T}}$ (X82254), Citrobacter freundi (M59291), Erwinia carotovora (M59149), Escherichia coli (M24911), Hafnia alve 
TABLE 1. Designations, origins, eukaryotic hosts, and 16S rDNA accession numbers of the strains analyzed in this study and the lengths of the 16S rDNA sequences determined

\begin{tabular}{|c|c|c|c|c|c|}
\hline Strain & Source & Origin of host & Host & $\begin{array}{l}\text { Sequence length } \\
\text { (nucleotides) }\end{array}$ & $\begin{array}{l}\text { Accession } \\
\text { no. }\end{array}$ \\
\hline \multicolumn{6}{|l|}{ Photorhabdus strains } \\
\hline WX1 & K. H. Nealson & Wisconsin & Unknown & 469 & Z77195 \\
\hline WX1F & K. H. Nealson & Wisconsin & Unknown & 469 & Z77196 \\
\hline WX2 & K. H. Nealson & Wisconsin & Unknown & 1,439 & $\mathrm{Z} 76746$ \\
\hline WX3 & K. H. Nealson & Wisconsin & Unknown & 469 & Z77197 \\
\hline WX4 & K. H. Nealson & Wisconsin & Unknown & 469 & Z77198 \\
\hline WX5 & K. H. Nealson & Wisconsin & Unknown & 469 & Z77199 \\
\hline WX6 & K. H. Nealson & Wisconsin & Unknown & 469 & $\mathrm{Z} 77200$ \\
\hline WX8 & K. H. Nealson & Wisconsin & Unknown & 469 & Z77201 \\
\hline WX9 & K. H. Nealson & Wisconsin & Unknown & 469 & Z77202 \\
\hline WX10 & K. H. Nealson & Wisconsin & Unknown & 469 & Z77203 \\
\hline WX11 & K. H. Nealson & Wisconsin & Unknown & 1,439 & $\mathrm{Z} 76747$ \\
\hline WX12 & K. H. Nealson & Wisconsin & Unknown & 469 & Z77204 \\
\hline WX13Z & K. H. Nealson & Wisconsin & Unknown & 469 & Z77205 \\
\hline WX14 & K. H. Nealson & Wisconsin & Unknown & 469 & Z77206 \\
\hline WX15 & K. H. Nealson & Wisconsin & Unknown & 469 & Z77207 \\
\hline V16 & K. H. Nealson & Australia & Heterorhabditis bacteriophora & 1,444 & Z76741 \\
\hline Q614 & K. H. Nealson & Australia & Unknown & 1,452 & Z76749 \\
\hline $\operatorname{Tn}-5^{*} 2$ & K. H. Nealson & Florida & Unknown & 1,428 & $\mathrm{Z76740}$ \\
\hline $\mathrm{Hm}, 1^{\circ}$ and $2^{\circ}$ & K. H. Nealson ${ }^{a}$ & Georgia & H. bacteriophora & 1,439 & Z76742 \\
\hline Hm Hyper ${ }^{b}$ & K. H. Nealson & Georgia & H. bacteriophora & 469 & Z77208 \\
\hline HP88 & R. Georgis & Utah & H. bacteriophora & 1,439 & $\mathrm{Z} 76743$ \\
\hline IS-5 $5^{c}$ & I. Glazer & Israel & H. bacteriophora & 1,439 & $\mathrm{Z} 76745$ \\
\hline Moldavian & L. Gerritsen & Moldavia & H. bacteriophora & 469 & Z77186 \\
\hline Brecon $^{c}$ & L. Gerritsen & South Australia & H. bacteriophora & 1,439 & Z76744 \\
\hline Meg1 & K. H. Nealson & Ohio & Heterorhabditis megidis & 1,440 & $\mathrm{Z} 76750$ \\
\hline Meg2 & K. H. Nealson & Ohio & H. megidis & 1,446 & $\mathrm{Z76751}$ \\
\hline $\mathrm{HSH} 1,1^{\circ}$ and $2^{\circ}$ & K. Osterfeld & Germany & H. megidis & 469 & Z77188 \\
\hline $\mathrm{HSH} 3,1^{\circ}$ and $2^{\circ}$ & K. Osterfeld & Germany & H. megidis & 469 & Z77189 \\
\hline UK $211^{c}$ & A. Burnell & Great Britain & H. megidis & 469 & Z77193 \\
\hline HL81 $^{c}$ & P. Westerman & The Netherlands & H. megidis & 469 & $\mathrm{Z} 77190$ \\
\hline PE $87.3^{c}$ & P. Gerritsen & The Netherlands & H. megidis & 1,439 & $\mathrm{Z76748}$ \\
\hline PE 87.3, var PE pink & L. Gerritsen & The Netherlands & H. megidis & 469 & Z77191 \\
\hline PE87.3, var PE yellow & L. Gerritsen & The Netherlands & H. megidis & 469 & $\mathrm{Z77192}$ \\
\hline PEGB & L. Gerritsen & The Netherlands & H. megidis & 469 & Z77187 \\
\hline CHJG I & J. Grund & Switzerland & H. megidis & 469 & Z77194 \\
\hline P-Jun & L. Gerritsen & The Netherlands & H. megidis & 467 & Z77185 \\
\hline ATCC 43949 & K. H. Nealson & $\mathrm{CDC}^{d}$ & Human blood & 1,428 & $\mathrm{Z} 76752$ \\
\hline ATCC 43950 & K. H. Nealson & $\mathrm{CDC}$ & Human pretibial wound & 1,428 & Z76755 \\
\hline ATCC 43951 & K. H. Nealson & $\mathrm{CDC}$ & Leg wound & 1,426 & Z76754 \\
\hline ATCC 43952 & K. H. Nealson & $\mathrm{CDC}$ & Abdomen, submandible & 1,426 & $\mathrm{Z} 76753$ \\
\hline \multicolumn{3}{|l|}{$\begin{array}{l}\text { Xenorhabdus nematophilus } \\
\text { strains }\end{array}$} & Steinernema & & \\
\hline 703 & K. Nealson & & Steinernema carpocapsae & 467 & Z77209 \\
\hline $\mathrm{N} 2-4,1^{\circ}$ and $2^{\circ \mathrm{c}}$ & R. Georgis & Biosys & S. carpocapsae strain Mexicana & 1,437 & $\mathrm{Z} 76737$ \\
\hline Riobravis & P. Grewal & New Mexico & Steinernema riobrava & 1,437 & Z76738 \\
\hline \multicolumn{6}{|l|}{ Xenorhabdus bovienii strains } \\
\hline $\mathrm{SF} 22^{c}$ & L. Gerritsen & Finland & Steinernema feltiae & 467 & $\mathrm{Z} 77210$ \\
\hline Norv ${ }^{c}$ & L. Gerritsen & Norway & S. feltiae & 467 & $\mathrm{Z} 77211$ \\
\hline Sulc ${ }^{c}$ & L. Gerritsen & Unknown & S. feltiae & 467 & $\mathrm{Z} 77212$ \\
\hline Filip $^{c}$ & L. Gerritsen & Unknown & S. feltiae & 467 & $\mathrm{Z} 77213$ \\
\hline $\begin{array}{l}\text { Xenorhabdus japonicus } \\
\text { IAM } 14265^{\mathrm{T}}\end{array}$ & $\begin{array}{l}\text { Japanese Culture } \\
\text { Collection }\end{array}$ & Japan & Steinernema kushidai & 1,389 & Z76739 \\
\hline
\end{tabular}

${ }^{a}$ According to reference 4.

${ }^{b}$ Strain $\mathrm{Hm}$ Hyper is a mutant of the strain $\mathrm{Hm} 2^{\circ}$ form which has all of the $1^{\circ}$ form characteristics.

${ }^{c}$ Strain isolated by E. Szállás.

${ }^{d} \mathrm{CDC}$, Centers for Disease Control and Prevention, Atlanta, Ga.

(M59155), Pantoea agglomerans (L24784), Serratia marcescens (M59160), Yersinia enterocolitica (M59292), and Proteus vulgaris (X07652) were used as references. The reference sequences were obtained from the Ribosomal Database Project (20).

Analysis of 16S rDNA. Amplification of the 16S rDNA was carried out as described previously (22). PCR products were sequenced directly by using a Taq DyeDeoxy terminator cycle sequencing kit (Applied Biosystems, Foster City, Calif.) according to the manufacturer's protocol. The sequence reaction mixtures were electrophoresed by using an Applied Biosystems model 373A DNA se quencer.

Phylogenetic analysis. The $16 \mathrm{~S}$ rDNA sequences were compared with the existing 16S rDNA database for members of the family Enterobacteriaceae deposited in the Ribosomal Database Project (20). Similarity values were transformed into phylogenetic distance values that compensated for multiple substitutions at any given site in the sequence (19). The least-squares distance method of De Soete (8) and the Neighbor Joining (24) and Maximum Likelihood pro- 
grams contained in the PHYLIP package (14) were used in the construction of phylogenetic dendrograms. For calculation of bootstrap values 300 trees were analyzed by using the NJFIND and NJBOOT programs.

DNA-DNA reassociation studies. DNA was isolated by chromatography on hydroxyapatite by the procedure of Cashion et al. (7). DNA-DNA hybridization was carried out as described by Huß et al. (17) and Escara and Hutton (12) by using a Gilford System model 2600 spectrophotometer equipped with a Gilford model 2527-R thermoprogrammer and plotter. Renaturation rates were computed with the TRANSFER.BAS program (18).

Nucleotide sequence accession numbers. The 16S rDNA sequences determined in this study have been deposited in the EMBL database under accession numbers $\mathrm{Z} 76741$ to $\mathrm{Z} 76755$ (for almost complete sequences) and Z77195 to Z77213 (for partial sequences) (Table 1)

\section{RESULTS}

Analysis of almost complete 16S rDNA sequences. Almost complete $16 \mathrm{~S}$ rDNA sequences ranging in length from 1,428 to 1,452 nucleotides (93 to $96 \%$ of the E. coli $16 \mathrm{~S}$ rDNA sequence) were determined for 16 luminescent strains and two nonluminescent strains. The sequence of a stretch of 1,339 nucleotides of the $16 \mathrm{~S}$ rDNA of $X$. japonicus IAM $14265^{\mathrm{T}}$ was also determined. These sequences were compared to homologous sequences from the type strains of $P$. luminescens, $X$. nematophilus, $X$. bovienii, $X$. beddingii, and $X$. poinarii, two strains of $P$. luminescens (DSM 3369 and HSH2) (23), and one strain each of several species of the family Enterobacteriaceae. No differences were detected in the primary structures of the $16 \mathrm{~S}$ rDNAs of the primary phase variant $\left(1^{\circ}\right)$ and secondary phase variant $\left(2^{\circ}\right)$ of strain $\mathrm{Hm}$ and $X$. nematophilus $\mathrm{N} 2-4$.

The similarity values determined for the luminescent strains indicate that there is a high level of relatedness between the type strain of $P$. luminescens and the two previously analyzed strains of this species (levels of similarity, $>96 \%$ ). The two nonluminescent strains, strain Riobravis and the $1^{\circ}$ form of strain $\mathrm{N} 2-4$, are highly related to the type strain of $X$. nematophilus (levels of similarity, $>99.5 \%$ ). $X$. japonicus type strain IAM 14265 and the type strains of the other four Xenorhabdus species are separated by similarity values which range from 96.4 to $97.8 \%$. All Xenorhabdus strains could be clearly distinguished from strains of $P$. luminescens by the occurrence of a signature nucleotide sequence between positions 208 and 211 (E. coli numbering) of the $16 \mathrm{~S}$ rDNA. While strains of Xenorhabdus species have the sequence UUCG between these positions, all luminescent strains have a longer version (UGAA $\mathrm{AG})$. The levels of $16 \mathrm{~S}$ rDNA sequence similarity between the two genera ranged from 94 to $96 \%$, while the values determined for levels of similarity between strains of the genera Xenorhabdus and Photorhabdus and strains of other members of the enterobacteria were between 92 and $95 \%$. When the sequence of Proteus vulgaris was used as a root, phylogenetic trees based on distance matrix analysis data and maximumlikelihood analysis data grouped the genera Xenorhabdus and Photorhabdus as phylogenetic neighbors within the family Enterobacteriaceae. The two algorithms used produced similar patterns of relatedness, except for the branch point of $X$. beddingii. According to the distance matrix tree, all Xenorhabdus species formed a phylogenetically coherent cluster, while in the neighbor-joining tree $X$. beddingii formed an individual line of descent between $X$. nematophilus and the Photorhabdus cluster. In the distance matrix tree (Fig. 1), the bootstrap value of $63 \%$ obtained for the branching pattern of the Xenorhabdus cluster was significantly higher than the value obtained for the branching point of Xenorhabdus species (8\%), as determined by the neighbor-joining method (data not shown). Therefore, the relationships of the symbionts of entomopathogenic rhabditid nematodes are depicted in a distance matrix tree (Fig. 1).

All luminescent strains grouped with the type strain of $P$.

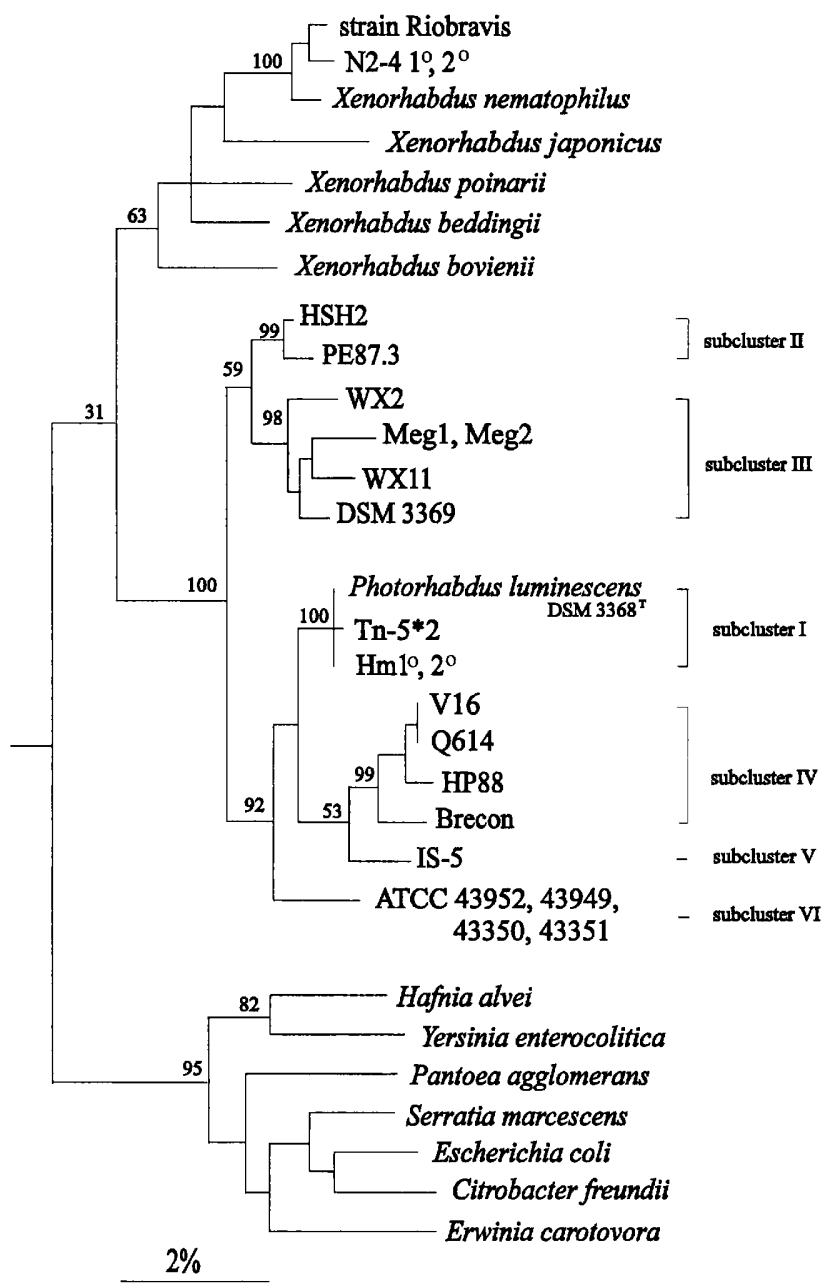

FIG. 1. Phylogenetic tree showing the relationships among members of the genera Xenorhabdus and Photorhabdus and members of the family Enterobacteriaceae. The analysis was based on 1,436 nucleotides of the $16 \mathrm{~S}$ rDNA. Strains separated by a commas have identical sequences. The sequence of Proteus vulgaris served as the root. Bar $=2$ nucleotide substitutions per 100 nucleotides. The numbers are bootstrap values.

luminescens, and this cluster was clearly separated from the Xenorhabdus species (bootstrap value, $100 \%$ ). The isolates of $P$. luminescens formed six related subclusters (subclusters I to VI), most of which were supported by bootstrap values of more than $98 \%$. Subcluster I contained the type strain of the species (DSM 3368), as well as strains $\mathrm{Hm}$ and strain $\mathrm{Tn}-5^{*} 2$, which were isolated in Georgia and Florida, respectively (level of similarity, 99.8\%). Subcluster II contained strain HSH2 (from Germany), which was analyzed previously (23), and strain PE87.3 (from The Netherlands) (level of similarity, 99.5\%). The phylogenetic neighbor subcluster III contained previously analyzed strain DSM 3369 (origin unknown), strains WX2 and WX11 (isolated in Wisconsin), and strains Meg1 and Meg2, which are independent isolates from the same location in Ohio (level of similarity, more than $98.8 \%$ ). Subcluster IV was composed of strains V16, Q614, and Brecon (all from Australia) and strain HP-88 (from Utah) (level of 98.9\% similarity, more than $98.9 \%$ ). Strain IS5 (from Israel) formed subcluster V, which had a low bootstrap value for the branch point of members of subclass IV (53\%). The 16S rDNA sequences of the four American Type Culture Collection strains from human 


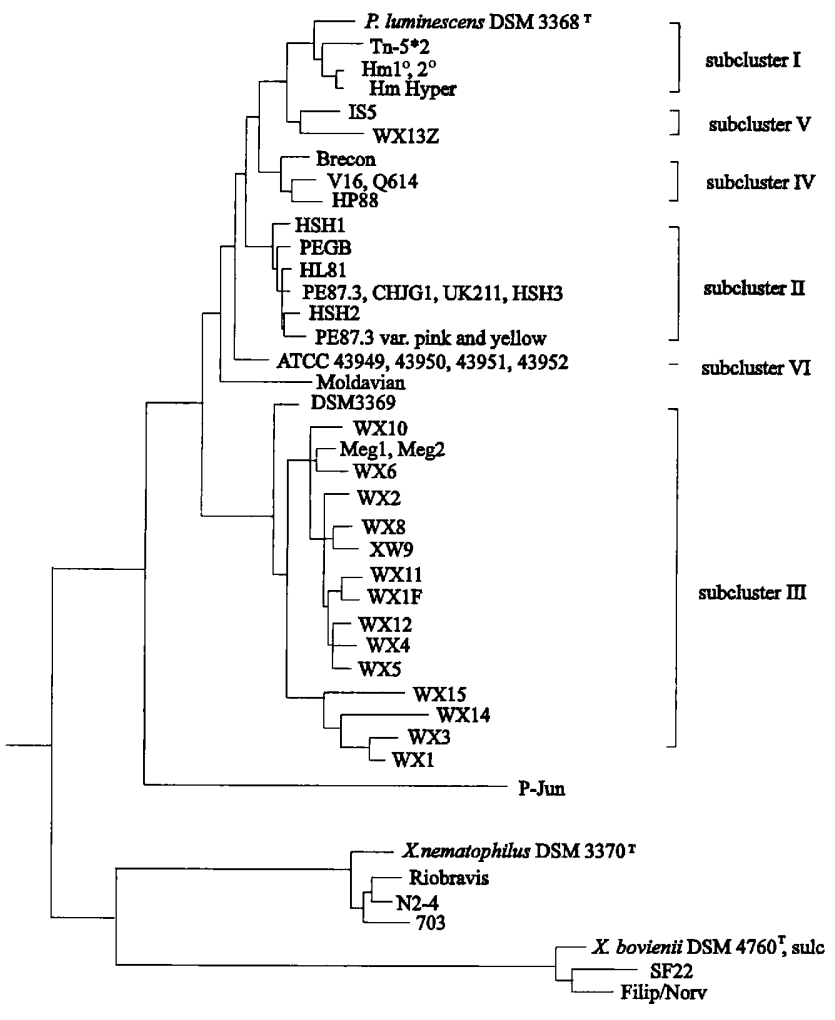

$5 \%$

FIG. 2. Phylogenetic tree showing the relationships among members of the genera Xenorhabdus and Photorhabdus. The analysis was based on 469 nucleotides of the 16S rDNA. Strains separated by commas have identical sequences. The sequence of Proteus vulgaris served as the root. Bar = five nucleotide substitutions per 100 nucleotides.

wounds and lesions were identical, and because these strains clustered separately from all other $P$. luminescens subclusters, they were described as members of subcluster VI.

Analyses of partial 16S rDNA sequences. In order to extend the phylogenetic analyses of $P$. luminescens strains, about 460 nucleotides from the $5^{\prime}$ terminus of the $16 \mathrm{~S}$ rDNA were analyzed for an additional 24 strains that were originally isolated from diverse areas (Great Britain, central Europe, Israel, North America [Wisconsin, Ohio, Florida, and Texas], and Australia); all of these strains were isolated from nematodes. In order to determine the phylogenetic depth of the species of the genus Xenorhabdus, isolates of $X$. nematophilus and $X$. bovienii were also included in this study. No differences were detected in the primary structures of the $16 \mathrm{~S}$ rDNAs of the $1^{\circ}$ and $2^{\circ}$ forms of strains $\mathrm{HSH} 1$ and $\mathrm{HSH} 3$, and there were no differences between the color variants of strain PE87.3. By using the sequences of two Xenorhabdus species to root the Photorhabdus cluster, the phylogenetic coherence of the luminescent strains was demonstrated with both of the algorithms used. A distance matrix tree is shown Fig. 2. All of the subclusters defined by the analysis of almost complete sequences were recovered, although the order of subclusters and the intersubcluster relatedness of strains changed. The branch point of subclusters I and II was supported by moderately high bootstrap values $(<60$ to $80 \%)$. Several strains of subcluster II, which contained the majority of the symbionts of the northwestern European strains of Heterorhabditis megidis, were found to have identical $16 \mathrm{~S}$ rDNA sequences in the stretch analyzed; these strains included strains from The Netherlands (P87.3), Switzerland (CHJG1), the United Kingdom (UK211) and Germany (HSH3). Subcluster III was composed mainly of Wisconsin (WX) strains, whose 16S rDNAs appear to be phylogenetically slightly more heterogeneous (level of dissimilarity, $2.5 \%$ ) than the $16 \mathrm{~S}$ rDNAs of the European strains (level of dissimilarity, $1 \%$ ). It should be noted that the Wisconsin strains came from different sites, and even from different soil habitats (prairie, birch trees, elm trees) and that the strains were isolated in separate baiting experiments on different days. The sites ranged over an area about $300 \mathrm{~km}$ in diameter, and the closest two sites were about $40 \mathrm{~km}$ from each other.

In addition to the subclusters identified on the basis of almost complete and partial 16S rDNA sequences, two new lineages emerged when additional strains were included. European strain Moldavian, isolated from Heterorhabditis bacteriophora, had a unique phylogenetic position. Strain P-Jun, isolated from The Netherlands, is an interesting organism as its branch point was between members of the genera Photorhab$d u s$ and Xenorhabdus. Based on biochemical evidence, this strain is an authentic member of the genus Photorhabdus, but its 16S rDNA has the signature sequence UUCG (positions 208 to 211) which is found in the $16 \mathrm{~S}$ rDNA sequences of Xenorhabdus species.

DNA-DNA reassociation experiments. In order to determine whether the subclusters that emerged from the analysis of a single gene could be recovered when genomic similarities were determined, DNA-DNA reassociation experiments were performed with selected strains from rDNA subclusters I to $\mathrm{V}$ (Table 2). These experiments were necessary as (i) DNA-DNA similarity values are needed to delimit species in the polyphasic approach to classification (27) and (ii) DNA similarities cannot be extrapolated from $16 \mathrm{~S}$ rDNA similarities because of the non-linear correlation between these two taxonomic parameters (25). The type strain of $P$. luminescens strain DSM 3368, and its relatives (subcluster I) exhibited moderately high levels of reassociation with members of subcluster IV (levels of similarity, 56 to $74 \%$ ). Similar values were obtained for members of subclusters II and III (levels of similarity, 56 to $76 \%$ ). Strain IS5, a member of subcluster $\mathrm{V}$, exhibited moderately high levels of reassociation with members of subclusters I, III, and IV (levels of similarity, 59 to $71 \%$ ). All other intersubcluster values were lower, ranging from 40 to $66 \%$ DNA similarity. The DNA similarity values determined for selected strains of $P$. luminescens and E. coli were less than $20 \%$ (data not shown).

\section{DISCUSSION}

Previous 16S rDNA analysis of four type strains of Xenorhabdus species and three strains of $P$. luminescens did not clearly separate the monospecific genus Photorhabdus from members of the genus Xenorhabdus (23). The branch point of $P$. luminescens and the branch points of the Xenorhabdus strains changed with the treeing algorithm used, and no conclusion could be drawn concerning whether the genus Xenorhabdus is a monophyletic taxon. Rainey et al. (23) discussed the possibility that the data set of available $16 \mathrm{~S}$ rDNA sequences for Xenorhabdus and Photorhabdus strains was too small to allow the algorithms to generate stable branching patterns for these highly related strains. Furthermore, the phylogenetic diversity of a species (e.g., the range of levels of $16 \mathrm{~S}$ rDNA dissimilarity among its strains) and the phylogenetic coherence of a species cannot be assessed if only the type strain of a species is included in $16 \mathrm{~S}$ rDNA studies. Analysis of the 
TABLE 2. Levels of DNA-DNA reassociation between representative strains of five $P$. luminescens 16S rDNA subclusters

\begin{tabular}{|c|c|c|c|c|c|c|c|c|c|c|c|c|}
\hline \multirow{2}{*}{ Subcluster } & \multirow{2}{*}{ Strain } & \multicolumn{11}{|c|}{$\%$ DNA-DNA reassociation with: } \\
\hline & & $\mathrm{Hm}, 1^{\circ}$ & $\mathrm{Hm}, 2^{\circ}$ & Hm Hyper & UK211 & CHJG I & WX8 & WX12 & WX13Z & HP88 & Brecon & IS- $5^{a}$ \\
\hline \multirow[t]{4}{*}{ I } & DSM $3368^{\mathrm{T}}$ & 100 & $\mathrm{ND}^{b}$ & 100 & 45 & 46 & 49 & 52 & 47 & 60 & 56 & 70 \\
\hline & $\mathrm{Hm}, 1^{\circ}$ & & ND & 95 & 53 & 46 & 50 & 63 & 63 & 74 & ND & 67 \\
\hline & $\mathrm{Hm}, 2^{\circ}$ & & & 99 & ND & ND & 46 & 59 & ND & ND & ND & ND \\
\hline & Hm Hyper & & & & ND & ND & ND & ND & ND & ND & ND & ND \\
\hline \multirow[t]{2}{*}{ II } & UK211 & & & & & 93 & 65 & 62 & 60 & 47 & ND & 61 \\
\hline & CHJG I & & & & & & 74 & 76 & 56 & 52 & ND & 59 \\
\hline \multirow[t]{3}{*}{ III } & WX8B & & & & & & & 88 & 88 & 46 & ND & 70 \\
\hline & WX12 & & & & & & & & 83 & 55 & ND & 63 \\
\hline & WX13Z & & & & & & & & & 55 & ND & 66 \\
\hline \multirow[t]{2}{*}{ IV } & HP88 & & & & & & & & & & 77 & 71 \\
\hline & Brecon & & & & & & & & & & & ND \\
\hline
\end{tabular}

\footnotetext{
${ }^{a}$ Strain IS-5 is a subcluster $\mathrm{V}$ strain.
}

${ }^{b} \mathrm{ND}$, not determined.

significantly enlarged data set generated in this study clearly indicated the phylogenetic separateness of the two genera.

The clustering of strains by and large correlates with the origins of the host nematodes. Among the nematode-symbiotic bacteria, subcluster I and III organisms are from southeastern and midwestern North America, respectively, while subcluster II and IV organisms are primarily from Europe and Australia, respectively. On the other hand, subcluster $\mathrm{V}$ is composed of strains from Israel and Wisconsin. The phylogenetic stability of two new sublines identified by partial $16 \mathrm{~S}$ rDNA analysis (strains Moldavian and P-Jun) needs to be tested by analyzing complete 16S rDNA sequences. Strain P-Jun, isolated in The Netherlands from a $H$. megidis host, represents the most deeply branching strain of all luminous strains investigated in this study. The presence of the enterobacterium-Xenorhabdus $16 \mathrm{~S}$ rDNA signature sequence at positions 208 to 211 together with the ability to exhibit fluorescence describes a new combination not previously detected. Strain P-Jun may represent a new species once more relatives have been isolated and studied by a polyphasic approach.

The four strains of subcluster VI are the only Photorhabdus strains for which a symbiotic association with entomopathogenic nematodes has not been demonstrated. These strains have identical 16S rDNA sequences, although the strains were isolated from different humans. Whether the patients were originally infected by nematode-bacterium-contaminated material or whether the Photorhabdus strains are free-living, opportunistic representatives of the genus cannot be determined yet.

The range of dissimilarity values for strains of subclusters I to $\mathrm{V}$ was as large as the range found for strains of $X$. nematophilus and $X$. bovienii. In order to decide whether these subclusters may correlate with genospecies, DNA reassociation studies were performed with a small number of representatives of each subcluster. Most binary intrasubcluster DNA similarity values were greater than $70 \%$, while most intersubcluster DNA similarity values were less than or around $70 \%$. The genomic heterogeneity of Photorhabdus strains confirmed previous work that demonstrated that there are individual subgroups within this species. Grimont et al. (16) found four DNA groups, and Farmer et al. (13) identified a fifth DNA group which was composed of isolates from human clinical specimens. Based on an analysis of a few strains, Boemare et al. (6) identified two DNA groups. A conflict between the previously published data and our data involves the affiliation of strain Hm. While Farmer et al. (13) found only $36 \%$ DNA similarity between the type strain of $P$. luminescens and strain $\mathrm{Hm}$, the
rDNA sequence data and the DNA reassociation values determined in this study indicate a much higher level of relatedness between these two strains. Certainly the identity of strain $\mathrm{Hm}$ distributed to different laboratories should be investigated.

Both rDNA sequencing studies and DNA-DNA reassociation studies confirmed the genomic heterogeneity of $P$. luminescens. As the identity of many host nematodes is unknown, it is not possible at this time to correlate all of the rDNA subclusters (subclusters I to V) with distinct nematode hosts. As shown by the information available, the strains of a defined rDNA subcluster are by and large homogeneous with respect to host species, which may indicate that the symbiotic association is ecologically significant. In conclusion, this study confirms and extends conclusions concerning the phylogenetic diversity of $P$. luminescens, which contains several genospecies. Certainly a search for exclusive subcluster-specific phenotypic properties, which is necessary to circumscribe centers of diversity in a polyphasic approach to classification, is called for.

\section{ACKNOWLEDGMENTS}

This study was supported by the U.S.-Hungarian Joint Fund no. $300 / 91$ and the COST 819 action, DEF grant no. 1434 .

\section{REFERENCES}

1. Akhurst, R. J. 1983. Taxonomic study of Xenorhabdus, a genus of bacteria symbiotically associated with insect-pathogenic nematodes. Int. J. Syst. Bacteriol. 33:38-45.

2. Akhurst, R. J. 1980. Morphological and functional dimorphism in Xenorhabdus spp., bacteria symbiotically associated with the insect pathogenic nematodes Neoaplectana and Heterorhabditis. J. Gen. Microbiol. 121:303309 .

3. Akhurst, R. J., and N. E. Boemare. 1988. A numerical taxonomic study of the genus Xenorhabdus (Enterobacteriaceae) and proposed elevation of the subspecies of $X$. nematophilus to species. J. Gen. Microbiol. 134:1835-1845.

4. Bleakley, B., and K. H. Nealson. 1988. Characterization of primary and secondary forms of Xenorhabdus luminescens strain Hm. FEMS Microbiol. Ecol. 53:241-250.

5. Boemare, N. E., and R. J. Akhurst. 1988. Biochemical and physiological characterization of colony form variants in Xenorhabdus spp. (Enterobacteriaceae). J. Gen. Microbiol. 134:751-761.

6. Boemare, N. E., R. J. Akhurst, and R. G. Mourant. 1993. DNA relatedness between Xenorhabdus spp. (Enterobacteriaceae), symbiotic bacteria of entomopathogenic nematodes, and a proposal to transfer $X$ luminescens to a new genus, Photorhabdus gen. nov. Int. J. Syst. Bacteriol. 43:249-255.

7. Cashion, P., M. A. Holder-Franklin, J. McCully, and M. Franklin. 1977. A rapid method for the base ratio determination of bacterial DNA. Anal Biochem. 81:461-466.

8. De Soete, G. 1983. A least squares algorithm for fitting additive trees to proximity data. Psychometrika 48:621-626.

9. Dunphy, G. B., and J. M. Webster. 1988. Virulence mechanisms of Hetero rhabditis heliothidis and its bacterial associate, Xenorhabdus luminescens, in non-immune larvae of the greater wax moth, Galleria mellonella. Int. J. Parasitol. 18:729-737. 
10. Dunphy, G. B., and J. M. Webster. 1988. Lipopolysaccharides of Xenorhabdus nematophilus (Entobacteriaceae) and their hemocyte toxicity in nonimmune Galleria mellonella (Insecta: Lepidoptera) larvae. J. Gen. Microbiol. 134:1017-1028.

11. Dunphy, G. B., T. A. Rutherford, and J. M. Webster. 1985. Growth and virulence of Steinemema glaseri influenced by different subspecies of Xenorhabdus nematophilus. J. Nematol. 17:476-482.

12. Escara, J. F., and J. R. Hutton. 1980. Thermal stability and renaturation of DNA in dimethylsulphoxide solutions: acceleration of renaturation rate. Biopolymers 19:1315-1327.

13. Farmer, J. J., III, J. H. Jorgensen, P. A. Grimont, R. J. Akhurst, G. O. Poinar, E. Ageron, G. V. Pierce, J. A. Smith, G. P. Carter, K. L. Wilson, and F. W. Hickman-Brenner. 1989. Xenorhabdus luminescens (DNA hybridization group) from human clinical specimens. J. Clin. Microbiol. 27:1594-1602.

14. Felsenstein, J. 1993. PHYLIP (phylogeny inference package), version 3.5c. University of Washington, Seattle.

15. Forst, S., and K. H. Nealson. 1996. Molecular biology of the symbioticpathogenic bacteria Xenorhabdus spp. and Photorhabdus spp. Microbiol. Rev. 60:21-43.

16. Grimont, P. A., A. G. Steigerwalt, N. E. Boemare, F. W. Hickman-Brenner, C. Deval, F. Grimont, and D. Brenner. 1984. Deoxyribonucleic acid relatedness and phenotypic study of the genus Xenorhabdus. Int. J. Syst. Bacteriol. 34:378-388.

17. Huß, V. A. R., H. Festl, and K. H. Schleifer. 1983. Studies on the spectrophotometric determination of DNA hybridization from renaturation rates. Syst. Appl. Microbiol: 4:184-192.

18. Jahnke, K.-D. 1992. BASIC computer program for evaluation of spectroscopic DNA renaturation data from GILFORD SYSTEM 2600 spectrophotometer on a PC/XT/AT type personal computer. J. Microbiol. Methods 15:61-73.
19. Jukes, T. H., and C. R. Cantor. 1969. Evolution of protein molecules, p. 21-132. In H. N. Munro (ed.), Mammalian protein metabolism. Academic Press, New York, N.Y.

20. Maidak, B. L., N. Larsen, J. McCaughey, R. Overbeeck, G. J. Olsen, K. Fogel, J. Blandy, and C. R. Woese. 1994. The Ribosomal Database Project. Nucleic Acids Res. 22:3485-3487.

21. Nishimura, Y., A. Hagiwara, T. Suzuki, and S. Yamanaka. 1994. Xenorhabdus japonicus sp. nov. associated with the nematode Steinernema kushidai. Word J. Microbiol. Biotechnol. 10:207-210.

22. Rainey, F. A., M. Dorsch, H. W. Morgan, and E. Stackebrandt. 1992. 16S rDNA analysis of Spirochaeta thermophila: its phylogenetic position and implications for the systematics of the order Spirochaetales. Syst. Appl. Microbiol. 15:197-202.

23. Rainey, F. A., R.-U. Ehlers, and E. Stackebrandt. 1995. Inability of the polyphasic approach to systematics to determine the relatedness of the genera Xenorhabdus and Photorhabdus. Int. J. Syst. Bacteriol. 45:379-381.

24. Saitou, N., and M. Nei. 1987. The neighbor-joining method: a new method for reconstructing phylogenetic trees. Mol. Biol. Evol. 4:406-425.

25. Stackebrandt, $\mathbf{E}_{\mathrm{o}}$ and B. M. Goebel. 1994. A place for DNA-DNA reassociation and 16S rRNA sequence analysis in the present species definition in bacteriology. Int. J. Syst. Bacteriol. 44:846-849.

26. Thomas, G. M., and G. O. Poinar, Jr. 1979. Xenorhabdus gen. nov., a genus of entomopathogenic nematophilic bacteria of the family Enterobacteriaceae. Int. J. Syst. Bacteriol. 29:352-360.

27. Wayne, L., D. J. Brenner, R. R. Colwell, P. A. D. Grimont, O. Kandler, M. I. Kíchevsky, L. H. Moore, W. E. C. Moore, R. G. E. Murray, E. Stackebrandt M. P. Starr, and H. G. Trüper. 1987. Report of the Ad Hoc Committee on Reconciliation of Approaches to Bacterial Systematics. Int. J. Syst. Bacteriol. 37:463-464. 